Article

\title{
Low-Temperature Catalytic CO Oxidation Over Non-Noble, Efficient Chromia in Reduced Graphene Oxide and Graphene Oxide Nanocomposites
}

\author{
Asma A. Ali ${ }^{1, *}$, Metwally Madkour ${ }^{2}{ }^{\circledR}$, Fakhreia Al Sagheer ${ }^{2}$, Mohamed I. Zaki ${ }^{3}$ and \\ Ahmed Abdel Nazeer 2,4,*(D) \\ 1 Science Department, College of Basic Education, Public Authority of Applied Education and \\ Training (PAAET), P.O. Box 23167, Safat 13092, Kuwait \\ 2 Chemistry Department, Faculty of Science, Kuwait University, P.O. Box 5969, Safat 13060, Kuwait; \\ Metwally.madkour@ku.edu.kw (M.M.); f.alsagheer@ku.edu.kw (F.A.S.) \\ 3 Chemistry Department, Faculty of Science, Minia University, El-Minia 61519, Egypt; mizaki@mu.edu.eg \\ 4 Electrochemistry Laboratory, Physical Chemistry Department, National Research Centre, Dokki, P.O. 12622, \\ Giza, Egypt \\ * Correspondence: aaa.ali@paaet.edu.kw (A.A.A.); anazeer_nrc@yahoo.com (A.A.N.)
}

Received: 3 December 2019; Accepted: 8 January 2020; Published: 11 January 2020

\begin{abstract}
Herein, bare chromia nanoparticles $\left(\mathrm{Cr}_{2} \mathrm{O}_{3} \mathrm{NPs}\right)$ and chromia supported on reduced graphene oxide (rGO) and graphene oxide (GO) hybrids were synthesized, followed by characterization by means of FESEM, Raman spectroscopy, TGA, XRD, TEM/HRTEM, XPS and $\mathrm{N}_{2}$ sorptiometry. The investigated bare $\mathrm{Cr}_{2} \mathrm{O}_{3}$ and the hybrids $\left(\mathrm{Cr}_{2} \mathrm{O}_{3} / \mathrm{rGO}\right.$ and $\left.\mathrm{Cr}_{2} \mathrm{O}_{3} / \mathrm{GO}\right)$ were employed as catalysts for low-temperature $\mathrm{CO}$ oxidation. Compared with the other catalysts, the results revealed efficient catalytic activity using $\mathrm{Cr}_{2} \mathrm{O}_{3} / \mathrm{GO}$, which was attributed to its higher surface area together with the mixed oxidation state of chromium $\left(\mathrm{Cr}^{3+}\right.$ and $\left.\mathrm{Cr}^{>3+}\right)$. These are important oxidation sites that facilitate the electron mobility essential for $\mathrm{CO}$ oxidation. Moreover, the presence of carbon vacancy defects and functional groups facilitate the stabilizing of $\mathrm{Cr}_{2} \mathrm{O}_{3} \mathrm{NPs}$ on its surface, forming a thermally stable hybrid material, which assists the $\mathrm{CO}$ oxidation process. $\mathrm{The} \mathrm{Cr}_{2} \mathrm{O}_{3} / \mathrm{GO}$ hybrid is a promising low-cost and efficient catalyst for $\mathrm{CO}$ oxidation at low temperatures. The higher activity of graphene oxide supported $\mathrm{Cr}_{2} \mathrm{O}_{3}$ NPs can provide an efficient and cost-effective solution to a prominent environmental problem.
\end{abstract}

Keywords: chromium oxide NPs; $\mathrm{CO}$ oxidation; $\mathrm{Cr}_{2} \mathrm{O}_{3}$ /carbonaceous hybrid; catalysis

\section{Introduction}

Carbon monoxide (CO) is a toxic and highly poisonous gas and is considered a silent killer that contributes indirectly to different environmental and health problems [1]. The main sources of $\mathrm{CO}$ are gases emitted from petroleum, chemical and petrochemical industries, and automobile emissions [1]. To overcome its toxicity, $\mathrm{CO}$ catalytic oxidation into less harmful carbon dioxide $\left(\mathrm{CO}_{2}\right)$ is an important strategy. Many researchers have employed different noble metals such as $\mathrm{Au}, \mathrm{Pt}$ and $\mathrm{Pd}$ as potential catalysts for $\mathrm{CO}$ oxidation; however, the issues of cost, poor stability, and sensitivity to impurities for deactivation limit their industrial applications [2]. Recently, low-temperature CO oxidation on non-noble metal catalysts has been an important research objective in order to overcome high cost and realize efficient results [3-5].

Metal oxide catalysts are regarded as promising materials for industrial and environmental CO oxidation reactions [6]. Their abundance, low cost and pronounced chemical stability make them a promising alternative to noble-metal based catalysts [7-9]. Studies that have hitherto been carried out 
show that transition metal oxides produce catalysts with high $\mathrm{CO}$ oxidation activity. Promoting the $\mathrm{CO}$ oxidation activity of oxide-based transition metals is still a point of enquiry, and further research is seeking to accomplish this objective. Chromia $\left(\mathrm{Cr}_{2} \mathrm{O}_{3}\right)$ is among the transition metal oxides that have been extensively researched [10]. Many researchers pay great attention to its physical and chemical characteristics [11-13]. This oxide demonstrated pronounced behavior in redox reactions, including the CO oxidation reaction $[14,15]$.

Cobalt oxide was reported to have nearly the same catalytic activity as noble metal catalysts for CO oxidation [16]. Nevertheless, because of the high surface energy of cobalt oxide's nanoparticles, it is ready to aggregate, which may lead to a reduction in catalytic activity. Supported metal nanoparticles are commonly used in heterogeneous catalytic processes, which are critical to various chemical reactions and can be used to solve the problem of individual metal oxides by protecting the in situ grown nanocatalysts from agglomeration [17]. This important supportive role improves the catalytic performance of metal nanoparticles (NPs).

Graphene and graphene oxide showed high surface-to-volume aspect ratios. Moreover, because of the presence of a carbon vacancy defect structure and different functional groups, metal ions can be easily adsorbed onto graphene's surface, forming thermally stable composite materials [18]. rGO and GO are widely used to support metallic nanoparticles in different applications due to their pronounced specific area and high stability [19]. On the basis of their unique properties, graphene and graphene oxide should be used as support materials for different heterogeneous catalysts [20,21]. Wang et al. studied the use of $\mathrm{rGO}-\mathrm{Co}_{3} \mathrm{O}_{4}$ catalysts for $\mathrm{CO}$ oxidation, and the results show remarkable activity and stability for the oxidation of $\mathrm{CO}$ using $30 \%$ rGO [22]. Wen et al. reported using an rGO-supported $\mathrm{Cr}_{2} \mathrm{O}_{3}$ catalyst for an oxygen reduction reaction (ORR), proving that hybrid $\mathrm{Cr}_{2} \mathrm{O}_{3} / \mathrm{rGO}$ has pronounced catalytic performance with high stability for ORR [23]. Xia et al. investigated $\mathrm{Cr}_{2} \mathrm{O}_{3} \mathrm{NPs}$ with a rGO hybrid as an efficient catalyst for electrochemical $\mathrm{N}_{2}$-to- $\mathrm{NH}_{3}$ conversion [24]. Up to the best of our knowledge, however, reports on the catalytic application of metal oxide hybrids with carbonaceous materials for $\mathrm{CO}$ oxidation are rare.

Consequently, the present first-of-a-type investigation studies the activity of unsupported and supported $\mathrm{Cr}_{2} \mathrm{O}_{3}$ NPs on carbonaceous compounds (rGO and GO) as a catalyst for $\mathrm{CO}$ catalytic oxidation at low temperatures. Obtained hybrids of $\mathrm{Cr}_{2} \mathrm{O}_{3} / \mathrm{rGO}$ and $\mathrm{Cr}_{2} \mathrm{O}_{3} / \mathrm{GO}$ showed pronounced catalytic activity for the oxidation of $\mathrm{CO}$ at low temperatures.

\section{Results and Discussion}

\subsection{Characterization of As-Prepared Samples}

Figure 1A,B shows the FESEM micrographs obtained for GO and rGO. It is clear that, after oxidation, the GO and rGO sheets were both crumpled. The reduction of the graphite sheets due to the distortion of their conjugated $\pi$-bond system is also clear. However, a flaky layered microstructure was only shown for GO (Figure 1A), whereas in rGO, the surface morphology was relatively close (Figure 1B) due to GO exfoliation during ultrasonic treatment. Raman spectra obtained for GO and rGO are compared in Figure 1C. The two broad peaks therein monitored are the D and G bands, which are the predominant features for carbon-based materials [25]. In the spectrum of GO, the peak at $1589 \mathrm{~cm}^{-1}$ is due to the $G$ band, whereas the peak at $1352 \mathrm{~cm}^{-1}$ is attributed to the $D$ band [25]. The spectrum of rGO shows the $G$ peak at $1582 \mathrm{~cm}^{-1}$ and the D peak at $1348 \mathrm{~cm}^{-1}$. These peak red-shifts are considered indicative of the recovery of $\mathrm{sp}^{2}$ domains [26] and, hence, the reduction of GO to rGO. 

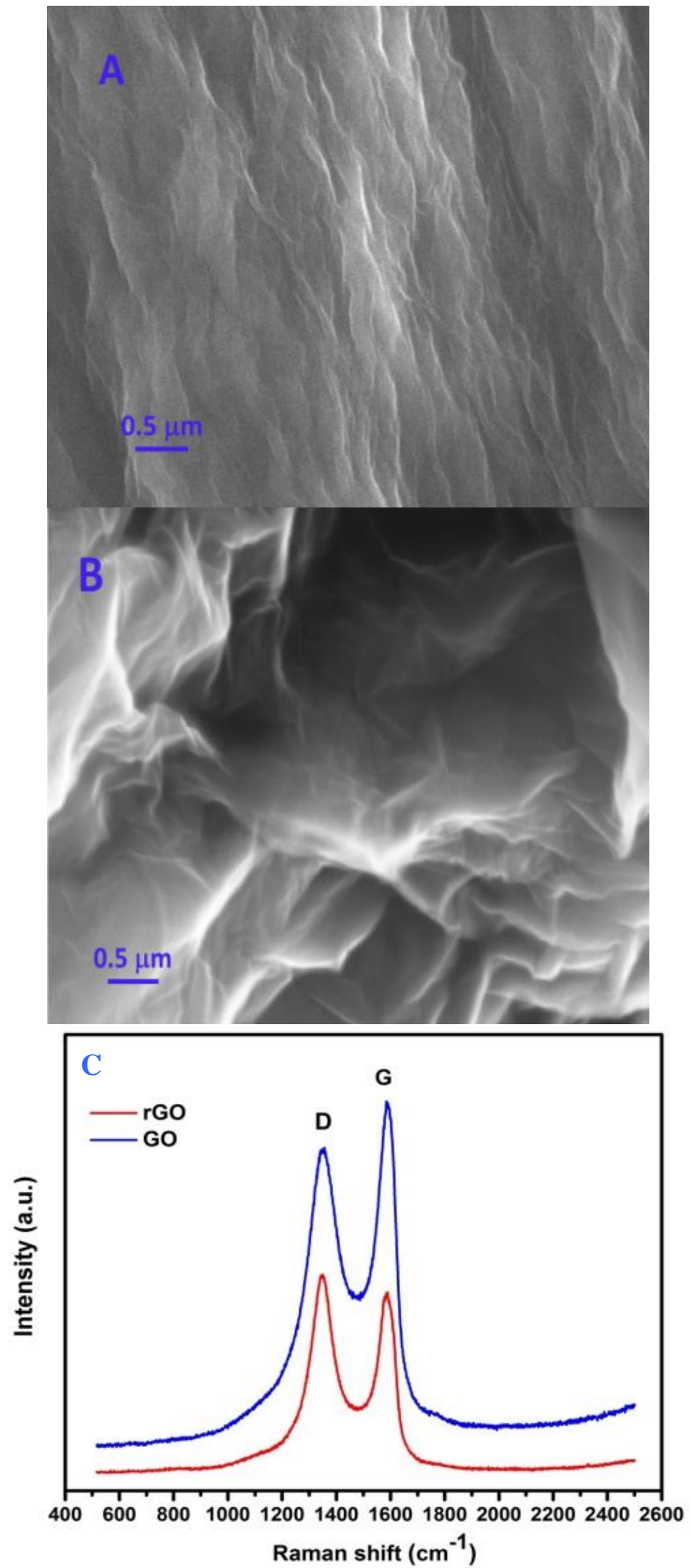

Figure 1. Typical FESEM images obtained for GO (A) and rGO (B) and their Raman spectra (C). 
TG curve obtained for the as-obtained chromia, i.e., the un-calcined $\mathrm{Cr}_{2} \mathrm{O}_{3} \cdot 4 \mathrm{H}_{2} \mathrm{O}$, displays two main decomposition steps, as shown in Figure 2. The first step is shown to undertake about a $25 \%$ mass loss maximized at $237^{\circ} \mathrm{C}$. This process is consistent with the removal of weakly held water molecules plus the dehydration to $\mathrm{Cr}_{2} \mathrm{O}_{3} \cdot \mathrm{H}_{2} \mathrm{O}(=2 \mathrm{CrOOH})$. The second step is shown to maximize at $415^{\circ} \mathrm{C}$, giving rise to mass loss of about $11 \%$, which is very close to the dehydration of $\mathrm{Cr}_{2} \mathrm{O}_{3} \cdot \mathrm{H}_{2} \mathrm{O}$ into $\mathrm{Cr}_{2} \mathrm{O}_{3}$ $(10.6 \%)$. These results verify the chemical composition of the parent chromium hydroxide compound and emphasize the appropriateness of the calcination temperature regime $\left(\geq 400{ }^{\circ} \mathrm{C}\right)$, applied for the thermal genesis of the $\mathrm{Cr}_{2} \mathrm{O}_{3}$ NPs from the parent hydroxide. Accordingly, we chose the calcination temperature of $600{ }^{\circ} \mathrm{C}$.

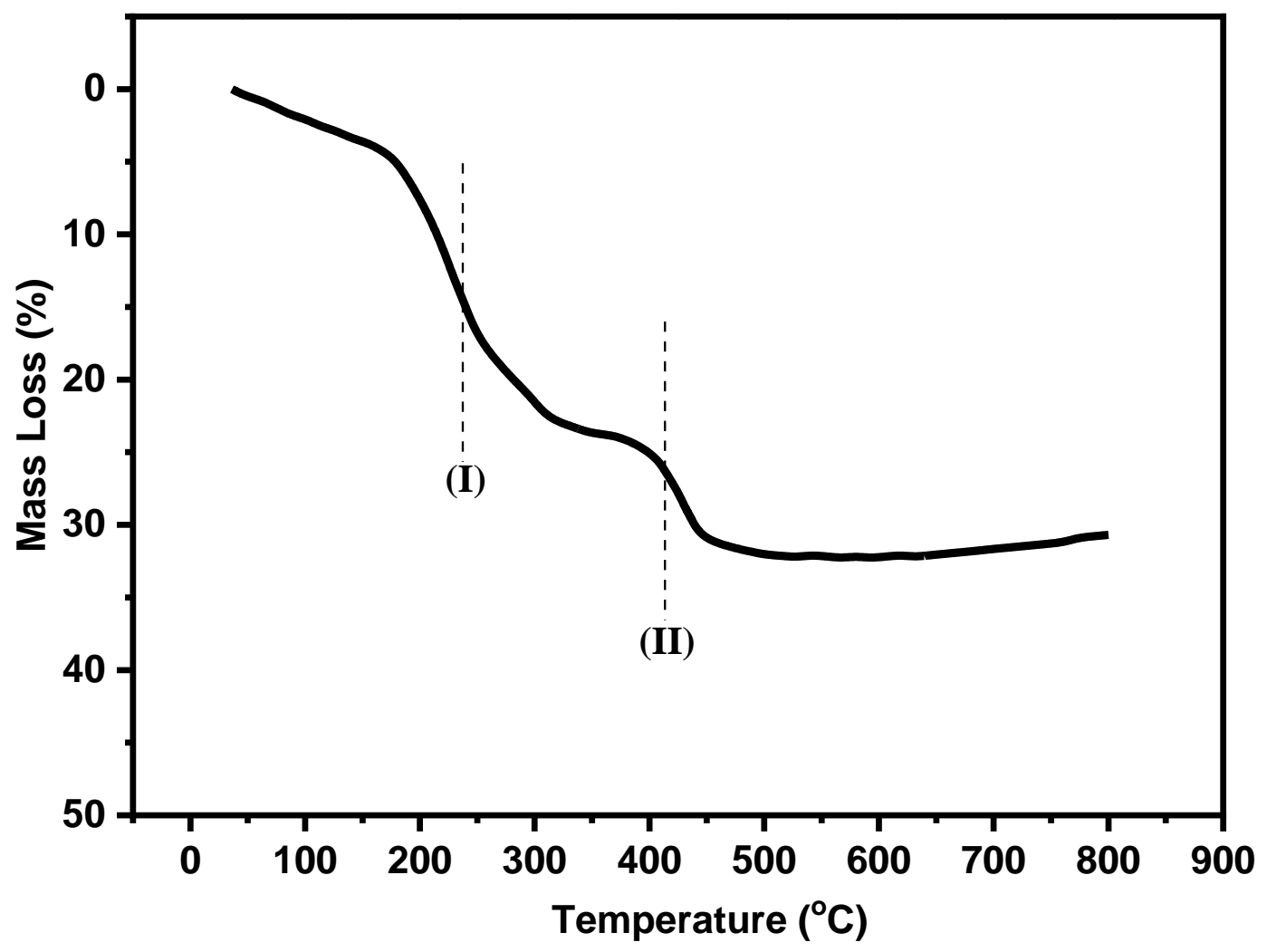

Figure 2. TG curve obtained for the as-obtained $\mathrm{Cr}_{2} \mathrm{O}_{3}$ tetrahydrate.

Figure 3 compares XRD powder diffractograms measured for $\mathrm{Cr}_{2} \mathrm{O}_{3}$ NPs and the hybrids $\mathrm{Cr}_{2} \mathrm{O}_{3} / \mathrm{rGO}$ and $\mathrm{Cr}_{2} \mathrm{O}_{3} / \mathrm{GO}$. In the case of $\mathrm{Cr}_{2} \mathrm{O}_{3}$, the monitored diffraction peaks are quite similar to the peaks filed for $\alpha-\mathrm{Cr}_{2} \mathrm{O}_{3}$ in JCPDS card no. 38-1479 [27]. Hence, $\alpha-\mathrm{Cr}_{2} \mathrm{O}_{3}$ is the sole XRD-detectable crystalline phase in the calcination products at $600{ }^{\circ} \mathrm{C}$. The average crystallite size determined for the $\alpha-\mathrm{Cr}_{2} \mathrm{O}_{3}$ particles was $32 \mathrm{~nm}$. In the case of $\mathrm{Cr}_{2} \mathrm{O}_{3} / \mathrm{GO}$ (Figure 3), the peak at around $2 \theta=10.6^{\circ}$ is assigned to the graphene oxide nanosheet, whereas the rest of the peaks monitored are indexed to the chromia NPs. As well as this, the XRD data of $\mathrm{Cr}_{2} \mathrm{O}_{3} / \mathrm{rGO}$ (Figure 3) is related to JCPDS no. 38-1479, and the diffraction peak at $2 \theta=24.8^{\circ}$ could be assigned to the rGO nanosheet. It is obvious that the peak at $2 \theta=10.6^{\circ}$ has disappeared, confirming the quantitative reduction of GO to $\mathrm{rGO}$ [28]. Hence, the XRD patterns of the synthesized hybrids $\mathrm{Cr}_{2} \mathrm{O}_{3} / \mathrm{rGO}$ and $\mathrm{Cr}_{2} \mathrm{O}_{3} / \mathrm{GO}$ reveal their effective preparation. 


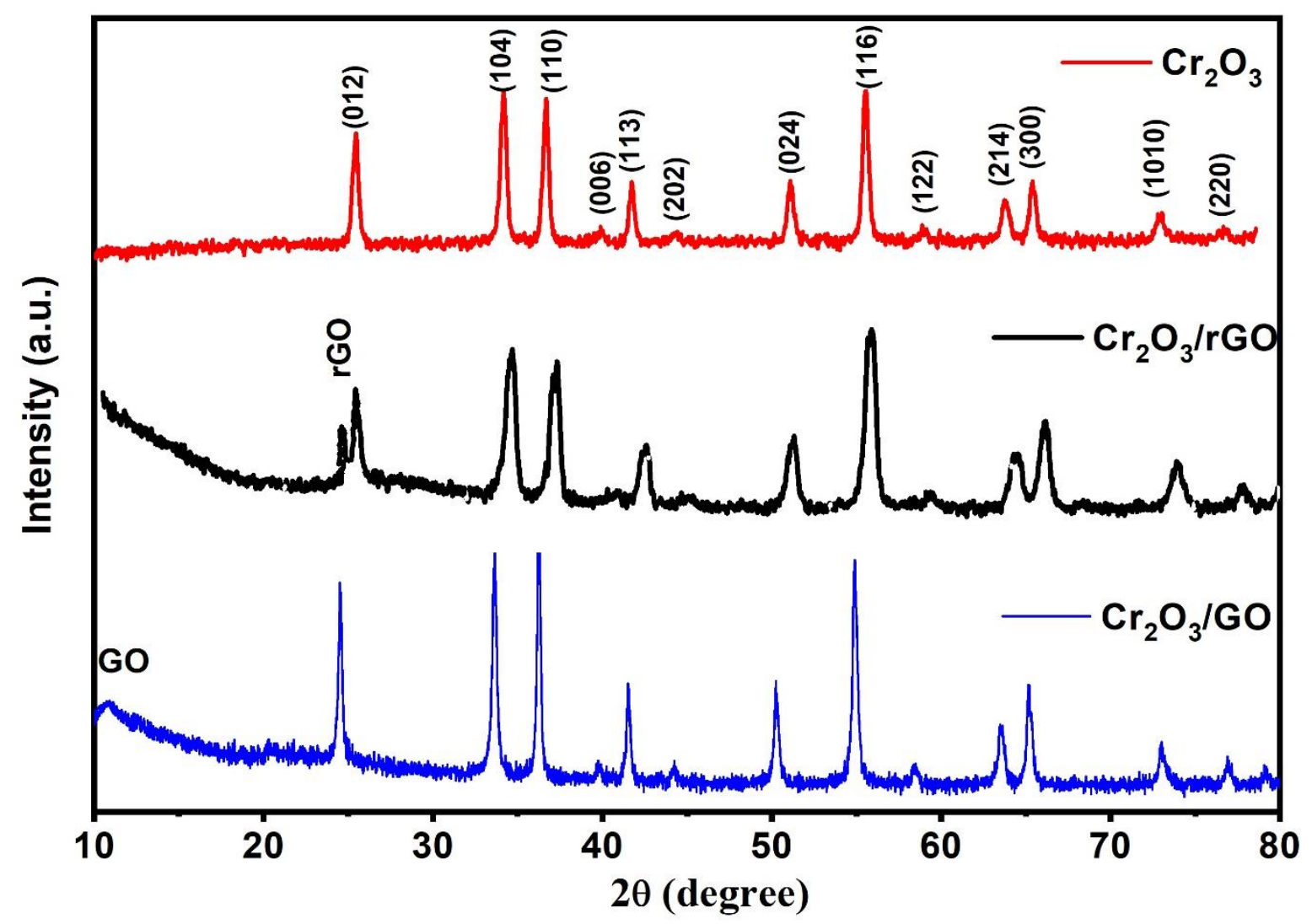

Figure 3. XRD patterns obtained for the bare $\alpha-\mathrm{Cr}_{2} \mathrm{O}_{3} \mathrm{NPs}$ and the hybrids $\mathrm{Cr}_{2} \mathrm{O}_{3} / \mathrm{rGO}$ and $\mathrm{Cr}_{2} \mathrm{O}_{3} / G O$.

TEM image obtained for $\alpha-\mathrm{Cr}_{2} \mathrm{O}_{3}$ NPs yielded after calcination at $600{ }^{\circ} \mathrm{C}$ is shown in Figure 4 A. It displayed well defined cubic-shaped nanoparticles of chromia. The average particle size for the obtained $\mathrm{Cr}_{2} \mathrm{O}_{3} \mathrm{NPs}$ at $600{ }^{\circ} \mathrm{C}$ is $47 \mathrm{~nm}$, which is higher than the XRD-determined average crystallite size $(32 \mathrm{~nm})$. This may reveal that the $\mathrm{Cr}_{2} \mathrm{O}_{3} \mathrm{NPs}$ are polycrystalline and are formed via coalescence and/or aggregation of the primary crystallites. Figure 4B,C show the TEM images of the $\mathrm{Cr}_{2} \mathrm{O}_{3} / \mathrm{rGO}$ and $\mathrm{Cr}_{2} \mathrm{O}_{3} / \mathrm{GO}$ hybrids, respectively. The images clearly reveal the distribution of relatively non-aggregating chromia NPs on the GO and rGO surfaces. The HRTEM image for $\mathrm{Cr}_{2} \mathrm{O}_{3}$ calcined at $600{ }^{\circ} \mathrm{C}$ is shown in Figure 4D. The image shows well-resolved lattice fringes with d-spacings of 0.264 $\mathrm{nm}$ for rhombohedral crystallites. Accordingly, the surface-abundant crystallite facet is 104 [23]. These findings are in good agreement with the XRD results, which indicate that the (104)-facet is the strongest reflecting crystal plane, with a d-spacing value of 2.61 (in $\AA$ ). 

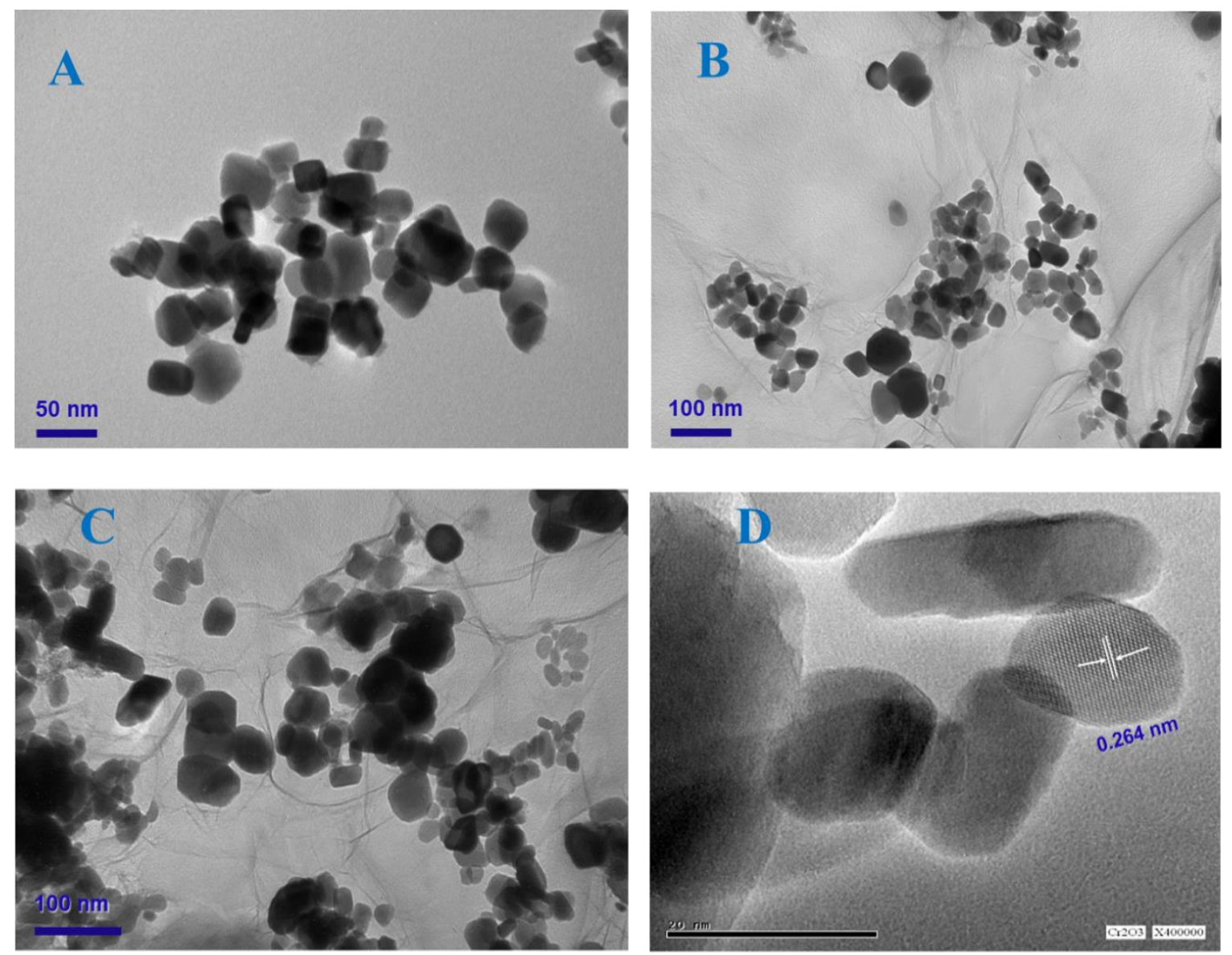

Figure 4. TEM micrographs obtained for $\mathrm{Cr}_{2} \mathrm{O}_{3} \mathrm{NPs}(\mathbf{A}) \mathrm{Cr}_{2} \mathrm{O}_{3} / \mathrm{rGO}(\mathbf{B})$ and $\mathrm{Cr}_{2} \mathrm{O}_{3} / \mathrm{GO}(\mathbf{C})$ hybrids. The panel (D) shows HRTEM micrograph obtained for $\mathrm{Cr}_{2} \mathrm{O}_{3}$.

XPS spectra for $\mathrm{Cr}(2 \mathrm{p})$ and $\mathrm{O}(1 \mathrm{~s})$ obtained for $\mathrm{Cr}_{2} \mathrm{O}_{3}$ NPs after calcination at $600{ }^{\circ} \mathrm{C}$ are shown in Figure $5 \mathrm{~A}, \mathrm{~B}$. $\mathrm{Cr}(2 \mathrm{p})$ electron $\mathrm{BE}$ values monitored at 586.1 and $587.8 \mathrm{eV}$ are attributed to $\mathrm{Cr} 2 \mathrm{p}_{1 / 2}$, and the values monitored at 576.5 and $578.6 \mathrm{eV}$ are assigned to $\mathrm{Cr} 2 \mathrm{p}_{3 / 2}$, respectively [29]. The lower $\mathrm{BE}$ of $576.5 \mathrm{eV}$ corresponds to the $\mathrm{Cr}^{3+}$ state [30]. The surface is also partially oxidized in order to form $\mathrm{Cr}^{>3+}$ ions, as previously reported by Fahim et al. [12]. The band at $578.6 \mathrm{eV}$ is assigned to the higher oxidation state $\mathrm{Cr}^{6+}\left(\mathrm{CrO}_{3}\right.$ species) [29]. The $\mathrm{O}(1 \mathrm{~s})$ spectrum monitors a broad peak deconvoluted into three subpeaks at binding energy 530, 531 and $532.4 \mathrm{eV}$. The peaks at 530 and $531 \mathrm{eV}$ are assignable to lattice oxygen, and this is in accordance with previously reported work [31,32]. The peak located at around $532.4 \mathrm{eV}$ was attributed to surface oxygen species and/or adsorbed surface hydroxyls [32]. 

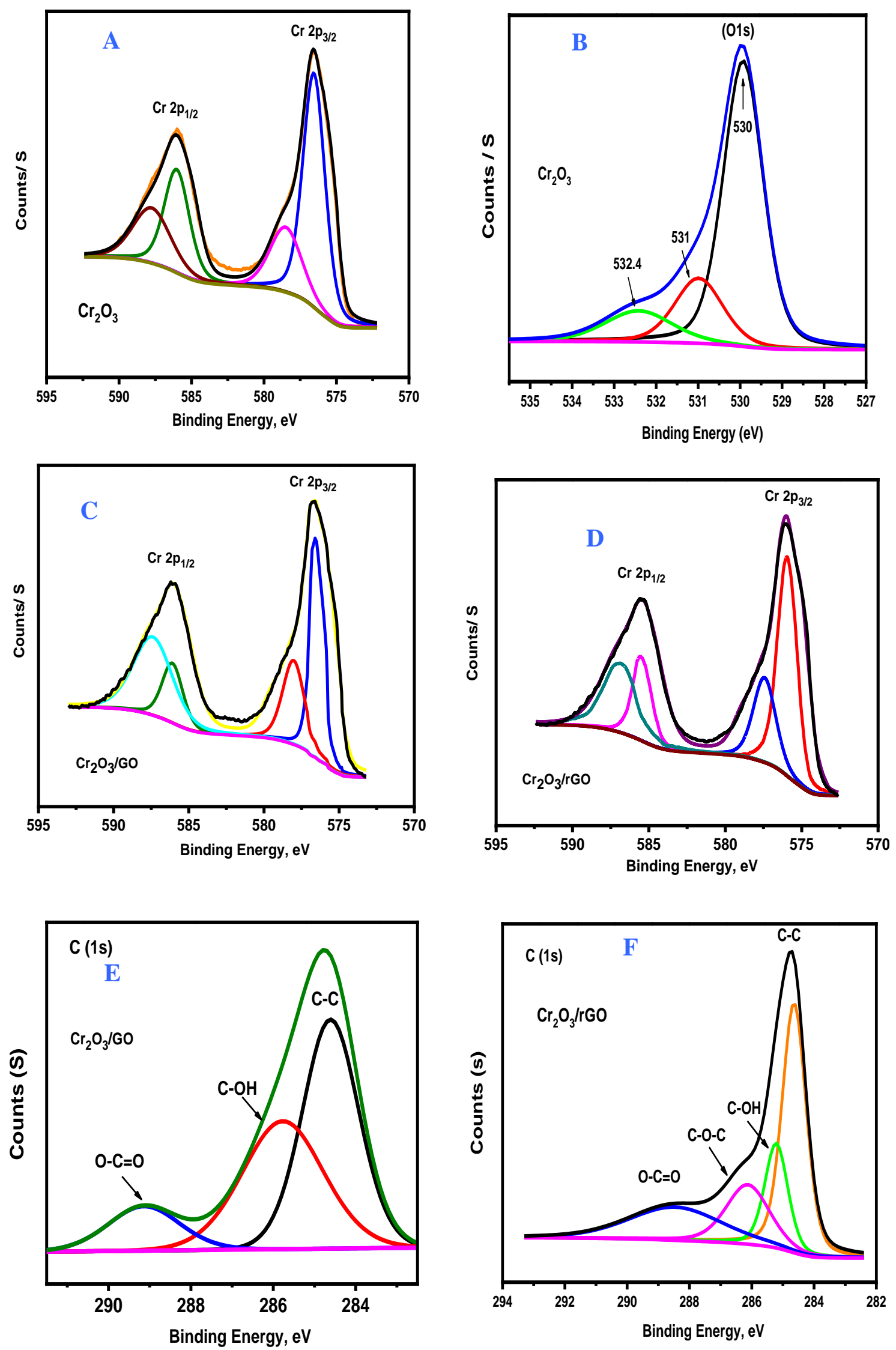

Figure 5. Cont. 

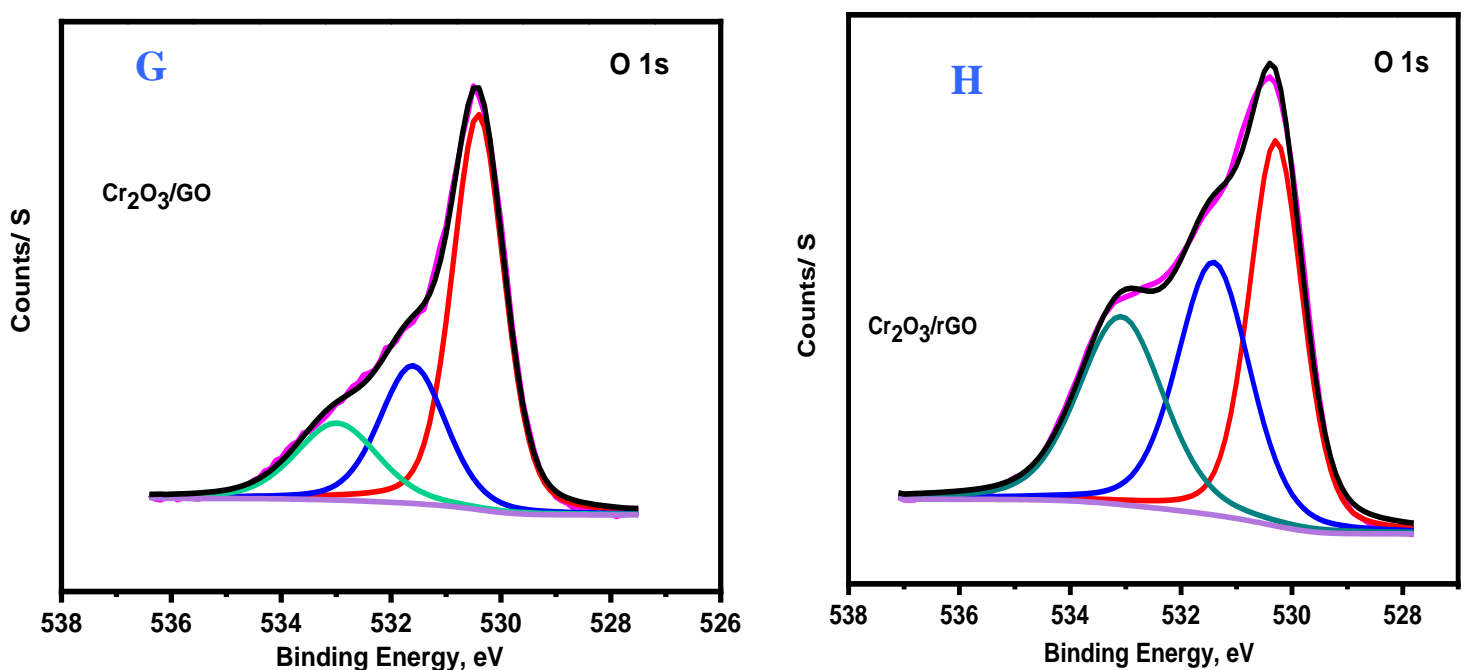

Figure 5. Deconvoluted XPS peaks of (A) $\mathrm{Cr}(2 \mathrm{p})$ and (B) $\mathrm{O}(1 \mathrm{~s})$ for the crystalline $\mathrm{Cr}_{2} \mathrm{O}_{3}$; (C) $\mathrm{Cr}(2 \mathrm{p})$, (E) $\mathrm{C}(1 \mathrm{~s})$ and (G) $\mathrm{O}(1 \mathrm{~s})$ peaks for $\mathrm{Cr}_{2} \mathrm{O}_{3} / \mathrm{GO}$; and (D) $\mathrm{Cr}(2 \mathrm{p})$, (F) $\mathrm{C}(1 \mathrm{~s})$ and (H) $\mathrm{O}(1 \mathrm{~s})$ peaks for $\mathrm{Cr}_{2} \mathrm{O}_{3} / \mathrm{rGO}$.

XPS spectra for the hybrids $\mathrm{Cr}_{2} \mathrm{O}_{3} / \mathrm{rGO}$ and $\mathrm{Cr}_{2} \mathrm{O}_{3} / \mathrm{GO}$ illustrate the presence of the chromium, oxygen and carbon spectra of the investigated hybrids. The chromium spectrum shows the same deconvoluted peaks obtained in the case of $\mathrm{Cr}_{2} \mathrm{O}_{3}$ (Figure $5 \mathrm{C}, \mathrm{D}$ ). In the $\mathrm{C}$ 1s spectrum of $\mathrm{Cr}_{2} \mathrm{O}_{3} / \mathrm{GO}$ (Figure 5E) there are also three peaks at $\mathrm{BEs}$ of 289.1 for the $\mathrm{O}-\mathrm{C}=\mathrm{O}, 285.8$ for $\mathrm{C}-\mathrm{OH}$, and $284.6 \mathrm{eV}$ for $\mathrm{C}-\mathrm{C}$ species. In the case of $\mathrm{Cr}_{2} \mathrm{O}_{3} / \mathrm{rGO}$ (Figure $5 \mathrm{~F}$ ), there was one more peak at $286.2 \mathrm{eV}$, consequent to the epoxide $(\mathrm{C}-\mathrm{O}-\mathrm{C})$ bond. The $\mathrm{C}-\mathrm{C}$ bonds in the case of $\mathrm{rGO}$ are more intense than in $\mathrm{GO}$. The intensity of the $\mathrm{C}-\mathrm{O}$ peak also decreased further in the case of reduced rGO than in GO. The dramatic decrease of the peak's intensity in the oxygen species and the sharp increase of the $\mathrm{C}-\mathrm{C}$ peak at 284.6 $\mathrm{eV}$ in the case of $\mathrm{Cr}_{2} \mathrm{O}_{3} / \mathrm{rGO}$ hybrid support the reduction process of $\mathrm{GO}$ to $\mathrm{rGO}$. As well as this, the decrease in the $\mathrm{Cr} / \mathrm{C}$ atomic ratio of $\mathrm{Cr}_{2} \mathrm{O}_{3} / \mathrm{rGO}(0.26)$, compared with $\mathrm{Cr}_{2} \mathrm{O}_{3} / \mathrm{GO}(0.34)$, is related to a higher carbon percentage in $\mathrm{rGO}$ than GO.

Moreover, the surface elemental analysis indicated that the carbon-to-oxygen atomic ratio $(\mathrm{C} / \mathrm{O})$ in the case of GO and rGO is 2.2 and 3.1, respectively. Increasing the C/O ratio for rGO confirms the partial removal of oxygen through the reduction process, which is in line with the XRD results.

The Brunauer-Emmett-Teller (BET) surface area of the prepared nanoparticles of $\mathrm{Cr}_{2} \mathrm{O}_{3} \mathrm{NPs}$ at $600{ }^{\circ} \mathrm{C}$ and the hybrids $\mathrm{Cr}_{2} \mathrm{O}_{3} / \mathrm{rGO}$ and $\mathrm{Cr}_{2} \mathrm{O}_{3} / \mathrm{GO}$ were measured. $\mathrm{N}_{2}$ adsorption-desorption isotherms of the examined materials are displayed in Figure 6. It is obvious that the isotherm obtained for bare $\mathrm{Cr}_{2} \mathrm{O}_{3}$ is a Type IV isotherm with a $\mathrm{H} 1$ type hysteresis loop, which implies a largely mesoporous surface [33]. Comparatively, the other two isotherms (hybrid catalysts) look like Type IV with a H3 type hysteresis loop that could be attributed to ink-bottle-like pores of varying radius, often produced by agglomerates or compacts of spheroidal particles of non-uniform size. The surface area values measured for $\mathrm{Cr}_{2} \mathrm{O}_{3}$ and the hybrids rGO-Cr $\mathrm{O}_{3}$ and $\mathrm{GO}-\mathrm{Cr}_{2} \mathrm{O}_{3}$ were found to be 39,112 and $144 \mathrm{~m}^{2} / \mathrm{g}$, respectively. Moreover, the corresponding mean pore volumes therefrom derived are $0.26,0.64$ and $0.93 \mathrm{~cm}^{3} \mathrm{~g}^{-1}$, respectively.

\subsection{Catalytic Activity}

Figure 7 demonstrates the catalytic activities for $\mathrm{CO}$ oxidation on the $\mathrm{Cr}_{2} \mathrm{O}_{3}$ NPs alone and the hybrid catalysts $\mathrm{Cr}_{2} \mathrm{O}_{3} / \mathrm{rGO}$ and $\mathrm{Cr}_{2} \mathrm{O}_{3} / \mathrm{GO}$ in the temperature range of $30-240{ }^{\circ} \mathrm{C} . \mathrm{T}_{100}$ is the temperature at which $100 \%$ of $\mathrm{CO}$ has been oxidized, while $\mathrm{T}_{50}$ is the light-off temperature. As illustrated in Figure 7, the conversion percentage of $\mathrm{CO}$ increased with the rise of the catalytic reaction temperature. The light-off temperature of $\mathrm{CO}$ oxidation $\left(\mathrm{T}_{50}\right)$ was achieved at 55,98 and $115^{\circ} \mathrm{C}$ in the presence of $\mathrm{Cr}_{2} \mathrm{O}_{3} / \mathrm{GO}, \mathrm{Cr}_{2} \mathrm{O}_{3} / \mathrm{rGO}$ and $\mathrm{Cr}_{2} \mathrm{O}_{3}$, respectively. The $\mathrm{Cr}_{2} \mathrm{O}_{3} / G O$ hybrid nanocatalyst showed the best complete $\mathrm{CO}$ conversion $\left(\mathrm{T}_{100}\right)$ values at $120^{\circ} \mathrm{C}$. 


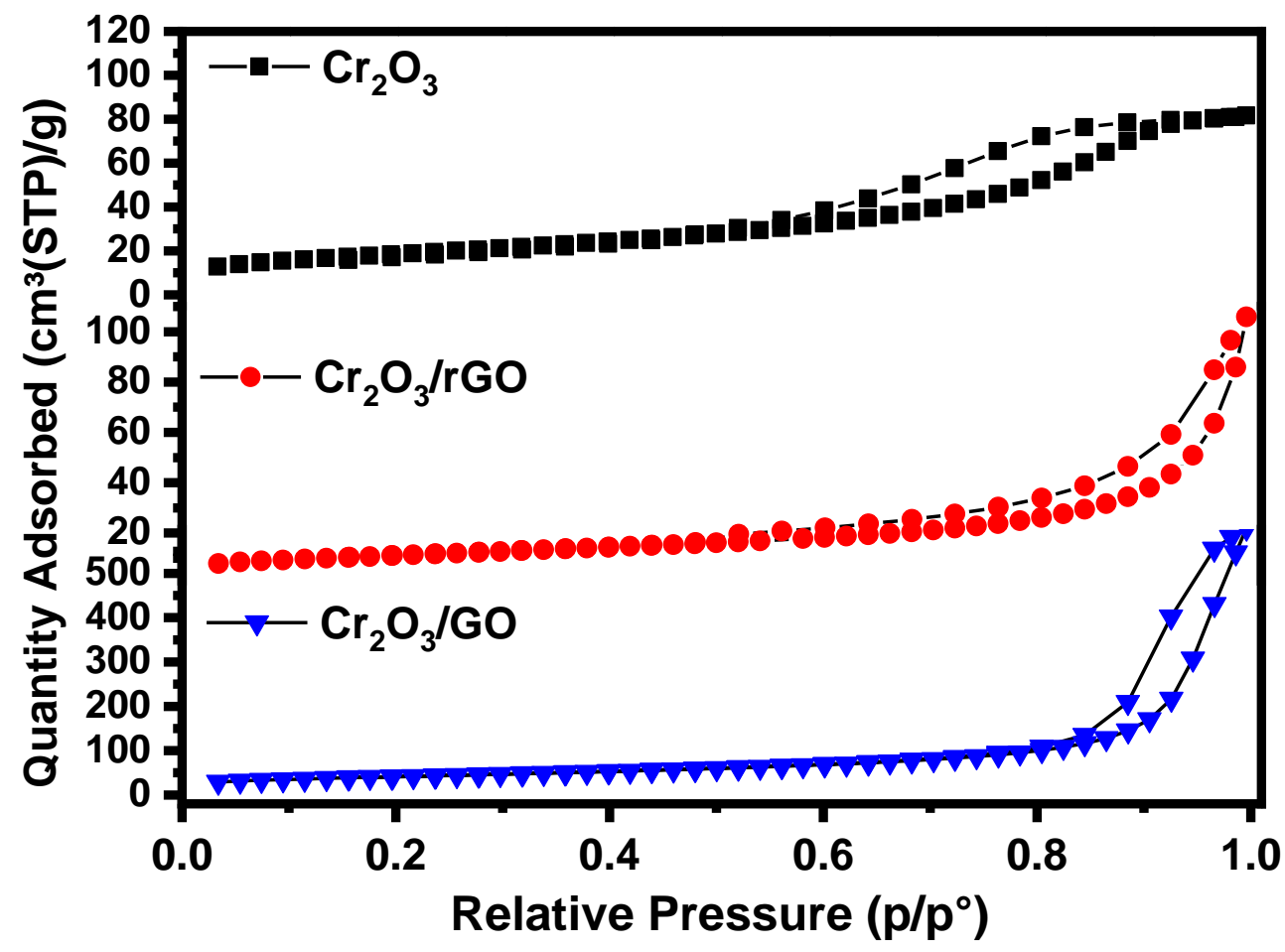

Figure 6. $\mathrm{N}_{2}$ adsorption-desorption isotherms for $\mathrm{Cr}_{2} \mathrm{O}_{3} \mathrm{NPs}$, and the hybrids $\mathrm{Cr}_{2} \mathrm{O}_{3} / \mathrm{rGO}$ and $\mathrm{Cr}_{2} \mathrm{O}_{3} / \mathrm{GO}$.

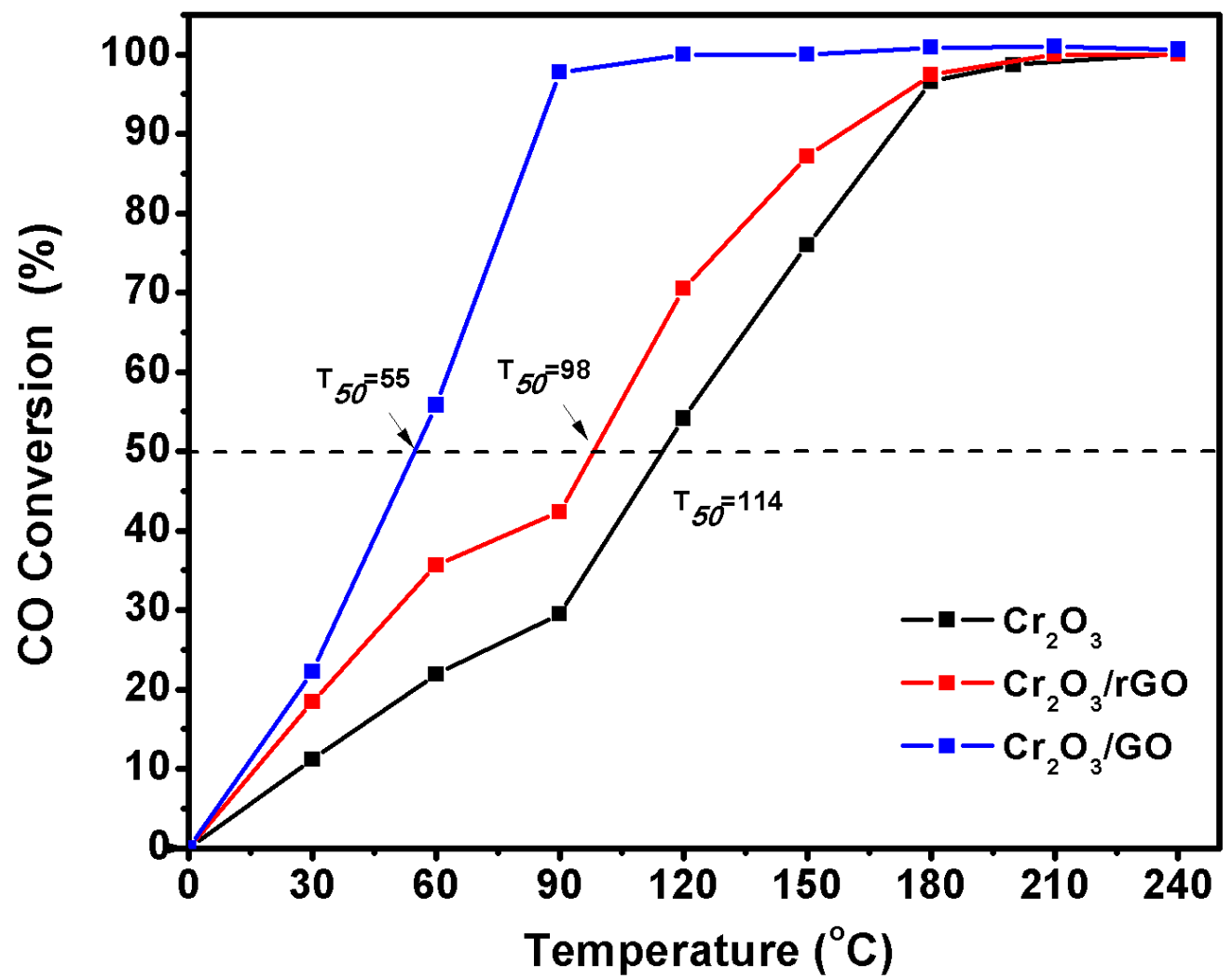

Figure 7. Catalytic activity for $\mathrm{CO}$ oxidation of $\mathrm{Cr}_{2} \mathrm{O}_{3} \mathrm{NPs}$ alone and the hybrids $\mathrm{Cr}_{2} \mathrm{O}_{3} / \mathrm{rGO}$ and $\mathrm{Cr}_{2} \mathrm{O}_{3} / \mathrm{GO}$ catalysts in the temperature range of $30-240{ }^{\circ} \mathrm{C}$.

The catalytic activity was attributed to higher surface area compared with the other catalysts and the mixed oxidation state of chromium $\left(\mathrm{Cr}^{3+}\right.$ and $\left.\mathrm{Cr}^{>3+}\right)$, which facilitates the electron mobility required 
for $\mathrm{CO}$ oxidation along with graphene oxide support. In Figure 7, the hybrid catalyst containing GO shows the highest $\mathrm{CO}$ conversion percent to $\mathrm{CO}_{2}$ due to the different functional groups present on $\mathrm{GO}$ compared with $\mathrm{rGO}$, which promote the $\mathrm{CO}$ oxidation process. The $\mathrm{Cr}_{2} \mathrm{O}_{3} / \mathrm{GO}$ hybrid nanocatalysts used in this study showed much higher catalytic activity than in previous reports, as shown in Table 1.

Table 1. $\mathrm{T}_{100}$ and $\mathrm{T}_{50}$ for $\mathrm{Cr}_{2} \mathrm{O}_{3}$ NPs alone and also for the hybrids $\mathrm{Cr}_{2} \mathrm{O}_{3} / \mathrm{rGO}$ and $\mathrm{Cr}_{2} \mathrm{O}_{3} / G O$, compared with different previously reported data on $\mathrm{Cr}_{2} \mathrm{O}_{3}$-based catalysts.

\begin{tabular}{|c|c|c|c|c|}
\hline Material & Experimental Conditions & $\mathrm{T}_{100},{ }^{\circ} \mathrm{C}$ & $\mathrm{T}_{50},{ }^{\circ} \mathrm{C}$ & Ref. \\
\hline $\mathrm{Cr}_{2} \mathrm{O}_{3}$ & $\begin{array}{l}45-46 \mathrm{~g}\left(80 \mathrm{~cm}^{3}\right) \text { of catalyst, gas } \\
\text { composition, } \mathrm{CO} \sim 1.2 \%, \mathrm{O}_{2} \sim 1.2 \% \text {, } \\
\text { balance He; gas rate- } 1400 \\
\mathrm{~cm}^{3} / \mathrm{min} \text {. }\end{array}$ & 340 & 265 & {$[34]$} \\
\hline $\begin{array}{c}\mathrm{CuO} / \mathrm{Cr}_{2} \mathrm{O}_{3} \\
\text { supported on silica }\end{array}$ & $\begin{array}{l}\text { The feed composition was } 2 \% \mathrm{CO}, \\
2 \% \mathrm{O}_{2} \text { in } \mathrm{He} .0 .1 \mathrm{~g} \text { of catalyst at a } \\
\text { flow rate of } 100 \mathrm{~mL} \mathrm{~min}^{-1}\end{array}$ & $\approx 500$ & 213 & [35] \\
\hline $\begin{array}{l}\mathrm{CuO} / \mathrm{Cr}_{2} \mathrm{O}_{3} \\
\text { supported on } \\
\text { Alumina }\end{array}$ & $\begin{array}{l}\text { The feed composition was } 2 \% \mathrm{CO} \text {, } \\
2 \% \mathrm{O}_{2} \text { in } \mathrm{He} .0 .1 \mathrm{~g} \text { of catalyst at a } \\
\text { flow rate of } 100 \mathrm{~mL} \mathrm{~min}^{-1}\end{array}$ & $\approx 320$ & 233 & [35] \\
\hline $\mathrm{Cr}_{2} \mathrm{O}_{3}-4$ & $\begin{array}{l}\text { The dose of examined material: } \\
250-300 \mathrm{mg} \\
\text { The mass ratio } 1 \mathrm{CO} \text { to } 3 \mathrm{O}_{2}\end{array}$ & 200 & 98 & [32] \\
\hline $\mathrm{Cr}_{2} \mathrm{O}_{3}-6$ & $\begin{array}{l}\text { The dose of examined material: } \\
250-300 \mathrm{mg} \\
\text { The mass ratio } 1 \mathrm{CO} \text { to } 3 \mathrm{O}_{2}\end{array}$ & 248 & 115 & [32] \\
\hline $\mathrm{Cr}_{2} \mathrm{O}_{3}-8$ & $\begin{array}{l}\text { The dose of examined material: } \\
250-300 \mathrm{mg} \\
\text { The mass ratio } 1 \mathrm{CO} \text { to } 3 \mathrm{O}_{2}\end{array}$ & 304 & 132 & [32] \\
\hline $\mathrm{Cr}_{2} \mathrm{O}_{3}$ & $\begin{array}{l}\text { The dose of examined material: } \\
300 \mathrm{mg} \\
\text { The mass ratio } 1 \mathrm{CO} \text { to } 3 \mathrm{O}_{2}\end{array}$ & 240 & 114 & Present \\
\hline $\mathrm{Cr}_{2} \mathrm{O}_{3} / \mathrm{rGO}$ & $\begin{array}{l}\text { The dose of examined material: } \\
300 \mathrm{mg} \\
\text { The mass ratio } 1 \mathrm{CO} \text { to } 3 \mathrm{O}_{2}\end{array}$ & 210 & 98 & Present \\
\hline $\mathrm{Cr}_{2} \mathrm{O}_{3} / \mathrm{GO}$ & $\begin{array}{l}\text { The dose of examined material: } \\
300 \mathrm{mg} \\
\text { The mass ratio } 1 \mathrm{CO} \text { to } 3 \mathrm{O}_{2}\end{array}$ & 120 & 55 & Present \\
\hline
\end{tabular}

The turnover frequency (TOF) for the investigated catalysts was calculated in terms of $\mu \mathrm{mol}$ of $\mathrm{CO}$ converted per $\mathrm{g}$ of the catalyst at $60^{\circ} \mathrm{C}$ to evaluate the intrinsic activity. The TOF of $\mathrm{Cr}_{2} \mathrm{O}_{3} \mathrm{NPs}$ and the TOFs of $\mathrm{Cr}_{2} \mathrm{O}_{3} / \mathrm{rGO}$ and $\mathrm{Cr}_{2} \mathrm{O}_{3} / \mathrm{GO}$ nanocatalysts were found to be 11,15 and $24 \mu \mathrm{mol} \mathrm{g}^{-1} \mathrm{~min}^{-1}$, respectively. According to the results, $\mathrm{Cr}_{2} \mathrm{O}_{3} / \mathrm{GO}$ exhibits the best intrinsic activity, which could be related to high surface area and the presence of redox couples $\left(\mathrm{Cr}^{3+} / \mathrm{Cr}^{>+3}\right)$ on chromia surfaces. These are important catalytic oxidation sites that facilitate the electron mobility required for $\mathrm{CO}$ oxidation.

In addition, the $\mathrm{Cr}_{2} \mathrm{O}_{3} / \mathrm{GO}$ hybrid catalyst revealed good stability at $240{ }^{\circ} \mathrm{C}$ compared with pure $\mathrm{Cr}_{2} \mathrm{O}_{3}$, which started to lose its conversion rate after $38 \mathrm{~h}$ and decreased up to $73 \%$ after $72 \mathrm{~h}$, as shown in Figure 8. The pronounced catalytic activity of $\mathrm{Cr}_{2} \mathrm{O}_{3} / \mathrm{GO}$ with respect to $\mathrm{Cr}_{2} \mathrm{O}_{3} \mathrm{NP}_{\mathrm{s}}$ is believed to be due to its higher surface area of $144 \mathrm{~m}^{2} / \mathrm{g}$ compared with $39 \mathrm{~m}^{2} / \mathrm{g}$ in the case of the pure $\mathrm{Cr}_{2} \mathrm{O}_{3} \mathrm{NPs}$. The decreased conversion rate is suggested to be a result of the aggregation of the pure $\mathrm{Cr}_{2} \mathrm{O}_{3} \mathrm{NPs}$ and the reduction of active oxygen on its surface. 


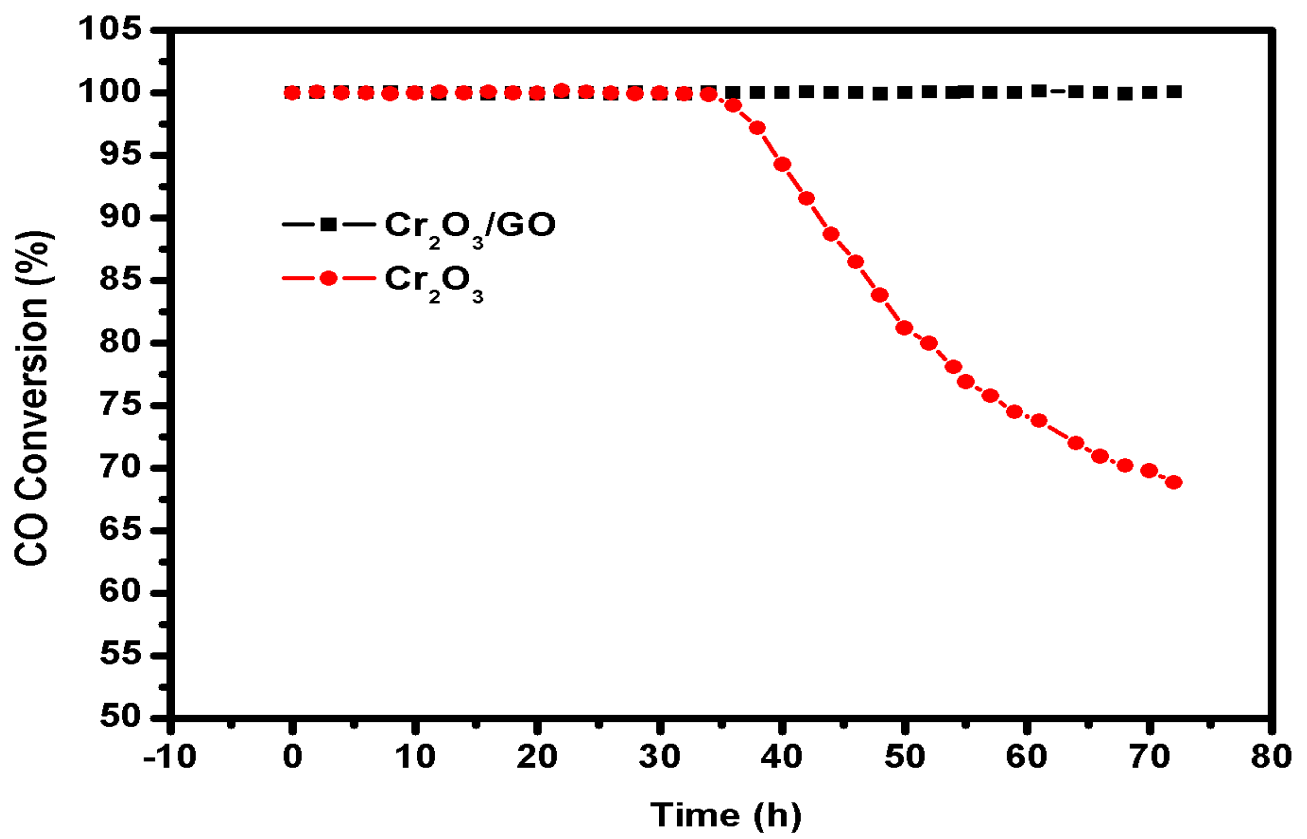

Figure 8. The stability test of the $\mathrm{Cr}_{2} \mathrm{O}_{3}$ catalyst and the hybrid $\mathrm{Cr}_{2} \mathrm{O}_{3} / \mathrm{GO}$ for $\mathrm{CO}$ oxidation at the reaction temperature of $240{ }^{\circ} \mathrm{C}$.

In the case of the hybrid catalysts, $\mathrm{Cr}_{2} \mathrm{O}_{3}$ is dispersed well in the carbonaceous material, which prevents its aggregation, therefore maintaining its stability at the conversion rate for a long time.

The proposed possible $\mathrm{CO}$ oxidation pathways over the $\mathrm{Cr}_{2} \mathrm{O}_{3} / \mathrm{GO}$ hybrid nanocatalyst are as follows: the molecular oxygen is dissociated into reactive oxygen species, and the adsorbed $\mathrm{CO}$ binds with active oxygen to form $\mathrm{CO}_{2}$ on the surface of $\mathrm{Cr}_{2} \mathrm{O}_{3}$ NPs. XPS results confirmed the presence of the redox couples $\left(\mathrm{Cr}^{3+} / \mathrm{Cr}^{>+3}\right)$ on chromia surfaces, which is significant for the required electron mobility for $\mathrm{CO}$ oxidation. The adsorbed $\mathrm{CO}$ molecules could be extracting the surface lattice oxygen from $\mathrm{Cr}_{2} \mathrm{O}_{3} \mathrm{NPs}$ to form $\mathrm{CO}_{2}$ along with surface oxygen vacancy. The $\mathrm{CO}_{2}$ molecules break away from the $\mathrm{Cr}_{2} \mathrm{O}_{3}$ surface, and the vacancy is filled with oxygen gas, which could be reacted with $\mathrm{CO}$ to form bidentate carbonate, which can then form $\mathrm{CO}_{2}$ again. Moreover, the oxygen vacancy could be filled by the active oxygen species passed through the graphene oxide. In conclusion, compared with $\mathrm{Cr}_{2} \mathrm{O}_{3}$, the $\mathrm{Cr}_{2} \mathrm{O}_{3} / \mathrm{GO}$ nanocatalyst shows the highest activity for $\mathrm{CO}$ oxidation due to the presence of graphene oxide substrate, which prevents the aggregation of $\mathrm{Cr}_{2} \mathrm{O}_{3}$ NPs and delivers more active sites. Its higher activity compared with $\mathrm{Cr}_{2} \mathrm{O}_{3} / \mathrm{rGO}$ is believed to be because of its higher surface area.

\section{Experimental Section}

\subsection{Materials}

Chromium nitrate nonahydrate $(\geq 99.99 \%)$, sodium hydroxide $(\geq 98 \%)$, graphite (fine powder extra pure), sodium nitrate ( $\geq 99.0 \%)$, sulfuric acid $(99.999 \%)$, potassium permanganate $(\geq 99.0 \%)$, hydrogen peroxide ( $30 \mathrm{wt} \%$ in $\mathrm{H}_{2} \mathrm{O}$ ) and hydrazine hydrate (RG) were purchased from Sigma-Aldrich, Taufkirchen, Germany.

\subsection{Preparation of $G O$ and $r G O$}

GO was synthesized according to the modified Hummer's method [36], wherein a $2 \mathrm{~g}$ portion of graphite powder was placed in a $250 \mathrm{~mL}$ beaker, then $1.0 \mathrm{~g}$ of $\mathrm{NaNO}_{3}$ and $46 \mathrm{~mL}$ of sulfuric acid were added with vigorous stirring in an ice bath at $0{ }^{\circ} \mathrm{C}$.Then, $6 \mathrm{~g}$ of potassium permanganate was placed slowly onto the mixture at $<20^{\circ} \mathrm{C}$. After 5 min we removed the ice bath, followed by heating out at 35 ${ }^{\circ} \mathrm{C}$ for $30 \mathrm{~min}$. Subsequently, a $92 \mathrm{~mL}$ aliquot of deionized water was poured slowly onto the mixture 
while increasing the temperature to $98^{\circ} \mathrm{C}$ and stirring continuously. This was maintained for another $30 \mathrm{~min}$. Subsequently, a $280 \mathrm{~mL}$ portion of hot water $\left(60^{\circ} \mathrm{C}\right)$ and $30 \mathrm{~mL}$ of hydrogen peroxide $\left(\mathrm{H}_{2} \mathrm{O}_{2}\right)$ aqueous solution $(30 \%)$ were added until there was no bubble evolution. Eventually, the mixture was centrifuged for $10 \mathrm{~min}$ (7200 rpm) with an aqueous solution of $\mathrm{HCl}(5 \%)$ to remove excess of manganese salt; the final powder was then washed using warm water until a reddish-brown color was obtained from the black color. Finally, GO was ultrasonically dispersed in water to form a stable solution of GO.

For the synthesis of $\mathrm{rGO}, 0.1 \mathrm{~g}$ of GO was sonicated in $20 \mathrm{~mL} \mathrm{H}_{2} \mathrm{O}$, followed by adding $100 \mathrm{~mL}$ of hydrazine hydrate and heating it using a microwave at $1000 \mathrm{~W}$ in two $30 \mathrm{~s}$ cycles. A black color was obtained, confirming the complete reduction of GO to rGO [22].

\subsection{Preparation of Bare Chromia Nanoparticles $\left(\mathrm{Cr}_{2} \mathrm{O}_{3} \mathrm{NPs}\right)$}

$\mathrm{Cr}_{2} \mathrm{O}_{3} \mathrm{NPs}$ were synthesized as follows: chromium nitrate was mixed with $\mathrm{NaOH}$ solution by stirring at $100{ }^{\circ} \mathrm{C}$ for one hour in order to obtain a dark green precipitate of $\mathrm{Cr}(\mathrm{OH})_{3}$. The precipitate was centrifuged and then washed with $\mathrm{H}_{2} \mathrm{O}$ to remove the $\mathrm{NaNO}_{3}$. Finally, the precipitate was dried at $110^{\circ} \mathrm{C}$ overnight, accompanied by calcination in air at $600^{\circ} \mathrm{C}$ for $5 \mathrm{~h}$ to obtain $\mathrm{Cr}_{2} \mathrm{O}_{3} \mathrm{NPs}$.

\subsection{Preparation of the Hybrid Catalysts $\left(\mathrm{Cr}_{2} \mathrm{O}_{3} / \mathrm{GO}\right.$ and $\left.\mathrm{Cr}_{2} \mathrm{O}_{3} / r G O\right)$}

In a $100 \mathrm{~mL}$ round bottom flask, $0.25 \mathrm{~g}$ of GO or rGO was dispersed in $75 \mathrm{~mL}$ of THF. Subsequently, $1.0 \mathrm{~g}$ of the prepared $\mathrm{Cr}_{2} \mathrm{O}_{3}$ NPs was added to the suspension and stirred continuously for $30 \mathrm{~min}$. Then, the mixture was refluxed for $24 \mathrm{~h}$ at $70^{\circ} \mathrm{C}$, accompanied by centrifuge and washing using THF. Finally, the prepared hybrids were thermally treated at $150{ }^{\circ} \mathrm{C}$ for $4 \mathrm{~h}$ in a hot air oven before use in order to improve crystallinity. The hybrid materials were prepared while maintaining the support material at $25 \%$, corresponding to $\mathrm{Cr}_{2} \mathrm{O}_{3} \mathrm{NPs}$.

\subsection{Characterization of Chromia NPs and Hybrid Catalysts}

XPS measurements were performed by a Thermo ESCA Lab 250xi (Waltham, MA, USA) equipped with $\mathrm{Mg} \mathrm{K} \alpha$ radiation (1253 eV). The XRD analysis was performed by a D8 Advance diffractometer (Leipzig, Germany) with a $\mathrm{Cu}$ target and nickel filter with $\mathrm{CuK} \alpha$ radiation $(\lambda=0.154056 \mathrm{~nm})$. Crystallite size was realized by adopting the line broadening technique and Scherrer's formula [37]. Raman spectra of GO and rGO were measured using RENISHAW (Oxfordshire, United Kingdom) via a Raman microscope, with an excitation wavelength of $514 \mathrm{~nm}$, a line of an Argon ion laser, and an exposure time of $10 \mathrm{~s}$. TEM data were recorded using a JEOL JEM 1230 microscope (Tokyo, Japan) at $120 \mathrm{kV}$. HRTEM was performed on a JEM-3010 JEOL ultra high-resolution electron microscope (Tokyo, Japan) operated at $300 \mathrm{kV}$ and $119 \mu \mathrm{A}$. FESEM was performed using SEM model (JSM-6300 JEOL, Tokyo, Japan). TG was performed by heating $10 \mathrm{mg}$ of test material at $10{ }^{\circ} \mathrm{C} / \mathrm{min}$ up to $800{ }^{\circ} \mathrm{C}$ in a dynamic $\left(50 \mathrm{~cm}^{3} / \mathrm{min}\right)$ atmosphere of air, using a model TA-50 Shimadzu thermal system (Kyoto, Japan) equipped with a workstation. $\mathrm{N}_{2}$ adsorption-desorption isotherms were measured on test samples at liquid nitrogen temperature $\left(-195^{\circ} \mathrm{C}\right)$, using an automatic Micromeritics sorptiometer model ASAP 2010 (Norcross, Georgia, USA) equipped with a degassing platform and online data acquisition and handling system powered with BET-based analytical software for surface area $\left(\mathrm{S}_{\mathrm{BET}} / \mathrm{m}^{2} \mathrm{~g}^{-1}\right)$ determination.

\subsection{Catalytic Activity Measurements}

The catalytic activity of the investigated catalysts for $\mathrm{CO}$ oxidation was tested using a tubular reactor adopting the same method previously reported [32]. The test catalyst powder was weighed out to $300 \mathrm{mg}$ and placed on a G1-porous quartz disc mounted in the middle of a tubular reactor with an inner diameter of $2 \mathrm{~cm}$ and a length of $15 \mathrm{~cm}$. The catalyst-bed aspect ratio (length to diameter) is 2 with short catalyst bed length of $1.3 \mathrm{~cm}$. A 300 Torr portion of $1 \mathrm{CO}+3 \mathrm{O}_{2}$ was expanded in the reactor at room temperature (RT), followed by a temperature increase in the range of $50-400{ }^{\circ} \mathrm{C} .50 \mu \mathrm{L}$ gas samples were withdrawn at different temperatures for analysis by a CP-GC6890 gas chromatograph 
(Santa Clara, CA, USA) equipped with a thermal conductivity detector (TCD) and a packed column with PORAPACK $Q$. The catalytic activity was expressed by the $\% C O$ conversion.

\section{Conclusions}

In summary, bare and supported chromium oxide hybrid nanocatalysts were successfully synthesized via a simple method and utilized for the low-temperature catalytic oxidation of CO. The $\mathrm{Cr}_{2} \mathrm{O}_{3} / \mathrm{GO}$ hybrid nanocatalyst showed the highest activity and stability for $\mathrm{CO}$ oxidation. The pronounced stability could be credited to the GO substrate. $\mathrm{Cr}_{2} \mathrm{O}_{3} / \mathrm{GO}$ showed $\mathrm{T}_{50}$ at $55^{\circ} \mathrm{C}$, and the complete conversion of $\mathrm{CO}$ was achieved at about $120^{\circ} \mathrm{C}$. This study promotes the development of transition metal oxide catalysts supported on carbonaceous compounds with significant efficiency and stability in low-temperature CO oxidation.

Author Contributions: A.A.A., F.A.S. and M.I.Z. outlined the work plan; A.A.N., M.M. and A.A.A. conducted the experimental part; A.A.N. and M.M. draw the figures and drafted the manuscript. All authors participated in the reviewing and publication processes of the article. All authors have read and agreed to publish this version of the manuscript.

Funding: This research was funded by [Kuwait Foundation for the Advancement of Sciences (KFAS)] grant number [PN17-14SC-01] and the APC was funded by [KFAS].

Acknowledgments: The authors acknowledge the support of this study by Kuwait Foundation for the Advancement of Sciences, under Grant Number [PN17-14SC-01] and Kuwait University, Research Administration general facility projects GS 01/01, GS 01/05, GS 02/01, GE03/08 and GS 03/01. Additionally, help from the Nanoscopy Science Center is appreciated.

Conflicts of Interest: The authors declare no conflict of interest.

\section{References}

1. Bhardwaj, N.; Pandey, A.; Satpati, B.; Tomar, M.; Gupta, V.; Mohapatra, S. Enhanced CO gas sensing properties of $\mathrm{Cu}$ doped $\mathrm{SnO}_{2}$ nanostructures prepared by a facile wet chemical method. Phys. Chem. Chem. Phys. 2016, 18, 18846-18854. [CrossRef] [PubMed]

2. Qi, J.; Chen, J.; Li, G.; Li, S.; Gao, Y.; Tang, Z. Facile synthesis of core-shell Au@CeO ${ }_{2}$ nanocomposites with remarkably enhanced catalytic activity for CO oxidation. Energy Environ. Sci. 2012, 5, 8937-8941. [CrossRef]

3. Xie, X.; Li, Y.; Liu, Z.-Q.; Haruta, M.; Shen, W. Low-temperature oxidation of CO catalysed by $\mathrm{Co}_{3} \mathrm{O}_{4}$ nanorods. Nature 2009, 458, 746-749. [CrossRef] [PubMed]

4. Li, Y.; Peng, H.; Xu, X.; Peng, Y.; Wang, X. Facile preparation of mesoporous Cu-Sn solid solutions as active catalysts for CO oxidation. RSC Adv. 2015, 5, 25755-25764. [CrossRef]

5. Gonçalves, R.V.; Wojcieszak, R.; Wender, H.; Sato, C.; Dias, B.; Vono, L.L.R.; Eberhardt, D.; Teixeira, S.R.; Rossi, L.M. Easy Access to Metallic Copper Nanoparticles with High Activity and Stability for CO Oxidation. ACS Appl. Mater. Interfaces 2015, 7, 7987-7994. [CrossRef]

6. Chen, H.; Fu, J.; Zhang, P.; Peng, H.; Abney, C.W.; Jie, K.; Liu, X.; Chi, M.; Dai, S. Entropy-stabilized metal oxide solid solutions as CO oxidation catalysts with high-temperature stability. J. Mater. Chem. A 2018, 6, 11129-11133. [CrossRef]

7. Liu, J.; Jiang, L.; Tang, Q.; Zhang, B.; Su, D.S.; Wang, S.; Sun, G. Coupling Effect Between Cobalt Oxides and Carbon For Oxygen Reduction Reaction. ChemSusChem 2012, 5, 2315-2318. [CrossRef]

8. Mao, S.; Wen, Z.; Huang, T.; Hou, Y.; Chen, J. High-performance bi-functional electrocatalysts of 3D crumpled graphene-cobalt oxide nanohybrids for oxygen reduction and evolution reactions. Energy Environ. Sci. 2014, 7, 609-616. [CrossRef]

9. Ye, Y.; Kuai, L.; Geng, B. A template-free route to a $\mathrm{Fe}_{3} \mathrm{O}_{4}-\mathrm{Co}_{3} \mathrm{O}_{4}$ yolk-shell nanostructure as a noble-metal free electrocatalyst for ORR in alkaline media. J. Mater. Chem. 2012, 22, 19132-19138. [CrossRef]

10. Horie, M.; Nishio, K.; Endoh, S.; Kato, H.; Fujita, K.; Miyauchi, A.; Nakamura, A.; Kinugasa, S.; Yamamoto, K.; Niki, E.; et al. Chromium(III) oxide nanoparticles induced remarkable oxidative stress and apoptosis on culture cells. Environ. Toxicol. 2013, 28, 61-75. [CrossRef]

11. Borello, E.; Zecchina, A.; Coluccia, S.; Cerruti, L. Infrared study of surface properties of alpha-chromia. II. Oxygen chemisorption. J. Phys. Chem. 1971, 75, 2783-2790. [CrossRef] 
12. Fahim, R.B.; Gabr, R.M.; Zaki, M.I.; Mansour, S.A.A. Nonstoichiometry and surface characterization of chromia gel. J. Colloid Interface Sci. 1981, 81, 468-476. [CrossRef]

13. Fahim, R.B.; Zaki, M.I.; Yacoub, N.H. Water sorption in relation to surface defect structure of calcined chromia gel. J. Colloid Interface Sci. 1982, 88, 502-511. [CrossRef]

14. Ren, Y.; Ma, Z.; Qian, L.; Dai, S.; He, H.; Bruce, P.G. Ordered Crystalline Mesoporous Oxides as Catalysts for CO Oxidation. Catal. Lett. 2009, 131, 146-154. [CrossRef]

15. Fahim, R.B.; Zaki, M.I.; Gabr, R.M. Heterogeneous and/or homogeneous chromia-catalysed decomposition of hydrogen peroxide. Surf. Technol. 1981, 12, 317-326. [CrossRef]

16. Lin-hua, H.; Ke-qiang, S.; Qing, P.; Bo-qing, X.; Ya-dong, L. Surface active sites on $\mathrm{Co}_{3} \mathrm{O}_{4}$ nanobelt and nanocube model catalysts for CO oxidation. Nano Res. 2010, 3, 363-368.

17. Liu, H.; Wang, J.; Feng, Z.; Lin, Y.; Zhang, L.; Su, D. Facile Synthesis of Au Nanoparticles Embedded in an Ultrathin Hollow Graphene Nanoshell with Robust Catalytic Performance. Small 2015, 11, 5059-5064. [CrossRef]

18. Li, Y.F.; Zhou, Z.; Yu, G.T.; Chen, W.; Chen, Z.F. CO Catalytic Oxidation on Iron-Embedded Graphene: Computational Quest for Low-Cost Nanocatalysts. J. Phys. Chem. C 2010, 114, 6250-6254. [CrossRef]

19. Kumar, G.M.; Sampath, S.; Jeena, V.S.; Anjali, R. Carbon Monoxide Pollution Levels at Environmentally Different Sites. J. Ind. Geophys. Union 2008, 12, 31-40.

20. Li, Y.; Yu, Y.; Wang, J.-G.; Song, J.; Li, Q.; Dong, M.; Liu, C.-J. CO oxidation over graphene supported palladium catalyst. Appl. Catal. B Environ. 2012, 125, 189-196. [CrossRef]

21. Vats, T.; Dutt, S.; Kumar, R.; Siril, P.F. Facile synthesis of pristine graphene-palladium nanocomposites with extraordinary catalytic activities using swollen liquid crystals. Sci. Rep. 2016, 6, 33053. [CrossRef] [PubMed]

22. Wang, Y.; Chen, Z.-H.; Huang, J.; Li, G.-J.; Cao, J.-L.; Zhang, B.; Chen, X.-Y.; Zhang, H.-L.; Jia, L. Preparation and catalytic behavior of reduced graphene oxide supported cobalt oxide hybrid nanocatalysts for $\mathrm{CO}$ oxidation. Trans. Nonferrous Met. Soc. China 2018, 28, 2265-2273. [CrossRef]

23. Wen, C.; Gao, X.; Huang, T.; Wu, X.; Xu, L.; Yu, J.; Zhang, H.; Zhang, Z.; Han, J.; Ren, H. Reduced graphene oxide supported chromium oxide hybrid as high efficient catalyst for oxygen reduction reaction. Int. J. Hydrog. Energy 2016, 41, 11099-11107. [CrossRef]

24. Xia, L.; Li, B.; Zhang, Y.; Zhang, R.; Ji, L.; Chen, H.; Cui, G.; Zheng, H.; Sun, X.; Xie, F.; et al. $\mathrm{Cr}_{2} \mathrm{O}_{3}$ Nanoparticle-Reduced Graphene Oxide Hybrid: A Highly Active Electrocatalyst for $\mathrm{N}_{2}$ Reduction at Ambient Conditions. Inorg. Chem. 2019, 58, 2257-2260. [CrossRef] [PubMed]

25. Zhang, Y.; Ma, H.-L.; Zhang, Q.; Peng, J.; Li, J.; Zhai, M.; Yu, Z.-Z. Facile synthesis of well-dispersed graphene by g-ray induced reduction of graphene oxide. J. Mater. Chem. 2012, 22, 13064. [CrossRef]

26. Pham, V.H.; Cuong, T.V.; Hur, S.H.; Oh, E.; Kim, E.J.; Shin, E.W.; Chung, J.S. Chemical functionalization of graphene sheets by solvothermal reduction of a graphene oxide suspension in N-methyl-2-pyrrolidone. J. Mater. Chem. 2011, 21, 3371. [CrossRef]

27. Ma, Z.; Xiao, Z.; van Bokhoven, J.A.; Liang, C. A non-alkoxide sol-gel route to highly active and selective $\mathrm{Cu}-\mathrm{Cr}$ catalysts for glycerol conversion. J. Mater. Chem. 2010, 20, 755-760. [CrossRef]

28. Gupta, B.; Kumar, N.; Panda, K.; Kanan, V.; Joshi, S.; Visoly-Fisher, I. Role of oxygen functional groups in reduced graphene oxide for lubrication. Sci. Rep. 2017, 7, 45030. [CrossRef]

29. Gupta, P.; Bhargava, R.; Das, R.; Poddar, P. Static and dynamic magnetic properties and effect of surface chemistry on the morphology and crystallinity of $\mathrm{DyCrO}_{3}$ nanoplatelets. RSC Adv. 2013, 3, 26427-26432. [CrossRef]

30. Osman, A.I.; Abu-Dahrieh, J.K.; Rooney, D.W.; Halawy, S.A.; Mohamed, M.A.; Abdelkader, A. Effect of precursor on the performance of alumina for the dehydration of methanol to dimethyl ether. Appl. Catal. B Environ. 2012, 127, 307-315. [CrossRef]

31. Kadari, A.; Schemme, T.; Kadri, D.; Wollschläger, J. XPS and morphological properties of $\mathrm{Cr}_{2} \mathrm{O}_{3}$ thin films grown by thermal evaporation method. Results Phys. 2017, 7, 3124-3129. [CrossRef]

32. Bumajdad, A.; Al-Ghareeb, S.; Madkour, M.; al Sagheer, F. Non-noble, efficient catalyst of unsupported $\alpha-\mathrm{Cr}_{2} \mathrm{O}_{3}$ nanoparticles for low temperature CO Oxidation. Sci. Rep. 2017, 7, 14788. [CrossRef] [PubMed]

33. Lecloux, A.J. Catalysis-Science and Engineering; Anderson, J.R., Boudart, M., Eds.; Springer-Verlag: Berlin/Heidelberg, Germany, 1981; Volume 2, pp. 171-229.

34. Shelef, M.; Otto, K.; Gandhi, H. The oxidation of $\mathrm{CO}$ by $\mathrm{O}_{2}$ and by $\mathrm{NO}$ on supported chromium oxide and other metal oxide catalysts. J. Catal. 1968, 12, 361-375. [CrossRef] 
35. Pantaleo, G.; Liotta, L.F.; Venezia, A.M.; Deganello, G.; Ezzo, E.M.; El Kherbawi, M.A.; Atia, H. Support effect on the structure and $\mathrm{CO}$ oxidation activity of $\mathrm{Cu}-\mathrm{Cr}$ mixed oxides over $\mathrm{Al}_{2} \mathrm{O}_{3}$ and $\mathrm{SiO}_{2}$. Mater. Chem. Phys. 2009, 114, 604-611. [CrossRef]

36. Hummers, W.S.; Offeman, R.E. Preparation of graphitic oxide. J. Am. Chem. Soc. 1958, 80, 1339. [CrossRef]

37. Madkour, M.; Ali, A.A.; Nazeer, A.A.; al Sagheer, F.; Belver, C. A novel natural sunlight active photocatalyst of $\mathrm{CdS} / \mathrm{SWCNT} / \mathrm{CeO}_{2}$ heterostructure: In depth mechanistic insights for the catalyst reactivity and dye mineralization. Appl. Surf. Sci. 2020, 499, 143988. [CrossRef]

(C) 2020 by the authors. Licensee MDPI, Basel, Switzerland. This article is an open access article distributed under the terms and conditions of the Creative Commons Attribution (CC BY) license (http://creativecommons.org/licenses/by/4.0/). 